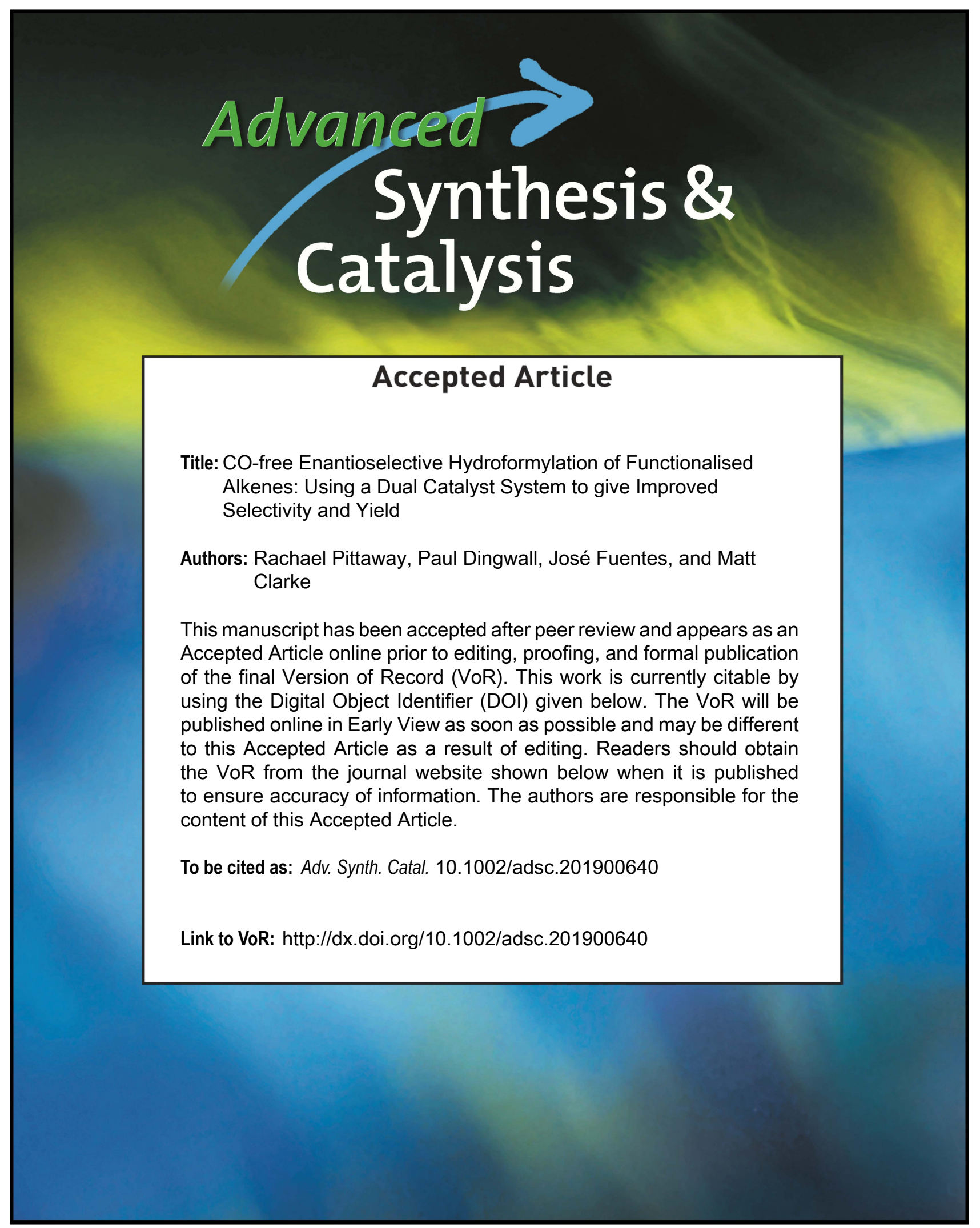




\title{
CO-free Enantioselective Hydroformylation of Functionalised Alkenes: Using a Dual Catalyst System to give Improved Selectivity and Yield
}

\author{
Rachael Pittaway, ${ }^{\text {a }}$ Paul Dingwall, ${ }^{\mathrm{b}}$ José. A. Fuentes, ${ }^{\text {a }}$ Matthew. L. Clarke ${ }^{\text {a* }}$ \\ a School of Chemistry, University of St Andrews, St Andrews, Fife, UK, KY16 9ST: mc28@st-andrews.ac.uk; +44 1334 \\ 463850 \\ b Current Address: School of Chemistry and Chemical Engineering, Queen's University Belfast, Belfast, BT9 5AG (UK)
}

Received: ((will be filled in by the editorial staff))

Supporting information for this article is available on the WWW under http://dx.doi.org/10.1002/adsc.201\#\#\#\#\#\#.((Please delete if not appropriate))

\begin{abstract}
The scope of carbon monoxide-free Asymmetric Transfer HydroFormylation (ATHF) procedures using a highly active single catalyst system derived from 1,2-bis((2,5)-diphenylphospholano)ethane as chiral ligand has been studied. This reveals some highly successful reactions, but also significant limitations. The development of a new protocol in which a catalyst for formaldehyde decomposition to $\mathrm{CO}$ and $\mathrm{H}_{2}$ is combined with the catalyst of choice for the subsequent asymmetric hydroformylation is described. This enables ATHF reactions that were problematic to be significantly improved. The new method has been used in the synthesis of several key precursors to biologically active molecules.
\end{abstract}

Keywords: Hydroformylation; Asymmetric Synthesis; Carbon monoxide surrogates; Regioselectivity; Rhodium

\section{Introduction}

There is no argument that the 'conventional' rhodium catalysed hydroformylation reaction is a valuable reaction; several examples are practised at huge scale for commodity and fine chemicals. ${ }^{[1]}$ While recognised as a tool in organic synthesis, ${ }^{[1]}$ it is perhaps underused in research-scale organic synthesis. One reason for this could be the initial nervousness of the non-expert in using $\mathrm{CO}$ gas, and the requirement to invest in some equipment to operate the reactions. For this reason, improved protocols for various types of CO-free hydroformylations are needed urgently. Some particularly desirable carbon monoxide surrogates are easily transportable and are available from waste biomass (e.g. formaldehyde, methanol, oxalates, formates etc.). It is therefore also conceivable that some larger scale hydroformylation could one day be operated using a $\mathrm{CO}$ surrogate should such methods be competitive with the use of syngas. The use of formaldehyde as a surrogate for both $\mathrm{CO}$ and hydrogen is highly appealing and has been the topic of research for some time. ${ }^{[2-5]}$ Probably the seminal work in this arena was by Morimoto and co-workers who discovered that a dual catalyst system could be used to conduct linear selective hydroformylations of alkenes using formaldehyde as CO source. ${ }^{[3]}$ More recently, our group and the Morimoto group reported in 2015 that enantioselective hydroformylation can be carried out using formaldehyde as a surrogate for syngas. ${ }^{[4,5]}$ These Asymmetric Transfer Hydroformylations are given the acronym ATHF, since AHF is sometimes used to refer to Asymmetric HydroFormylations.

Labelling studies by both groups came to the same conclusion; that the ATHF is a transfer hydroformylation from a practical point of view, but mechanistically a tandem process in which the catalyst is adept at both decomposition o. formaldehyde to syngas, and a highly reactive catalyst for low-pressure hydroformylation.

Both research studies relied on the use of the same ligand, Ph-BPE (1) (Fig. 1), ${ }^{[6]}$ combined with different $\mathrm{Rh}$ sources: $\left[\mathrm{Rh}(\mathrm{acac})(\mathrm{CO})_{2}\right]^{[4]}$ or $\left[\{\mathrm{RhCl}(\mathrm{cod})\}_{2}\right] .{ }^{[5]} \mathrm{In}$ order to fully appreciate the rarity of catalysts that can conduct the two steps of formaldehyde decomposition and hydroformylation in ATHF, Fig 1 shows the best conversion to aldehydes found for some well established hydroformylation ligands in this first phase of work. 
<smiles>c1ccc([PH2+]C2CC[C@@H](c3ccccc3)P2CCP2C(c3ccccc3)CC[C@H]2c2ccccc2)cc1</smiles>

$(R, R)-\mathrm{Ph}-\mathrm{BPE}, 1$<smiles>Cc1cc(C)c(C)c(-c2c(C)cc(C)c(C)c2OP(OCP2[C@H](c3ccccc3)CC[C@H]2c2ccccc2)Oc2ccccc2)c1</smiles>

$\left(S_{a x}, S, S\right)$-bobphos, 2

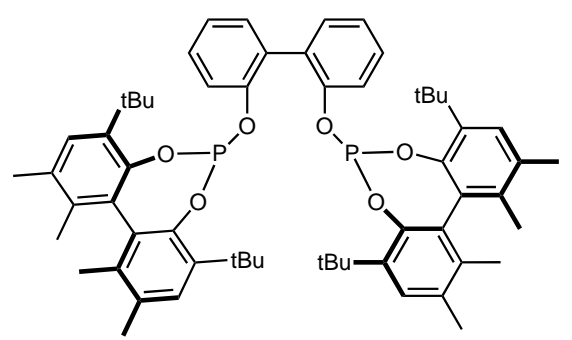

$(R, R)$-Kelliphite, 3<smiles>[2H]c1ccccc1C1N2C(=O)CCC(=O)N2[C@@H](c2ccccc2[2H])P1c1ccccc1[2H]</smiles>

$\operatorname{Bis}[(R, R, S)-D i a z a P h o s-S P E], 4$

$10 \%$<smiles>CC1(C)c2cccc(-c3ccccc3)c2Oc2c(-c3ccccc3)cccc21</smiles>

Xantphos, 5

rac-BINAP, 6

$0 \%$

$0 \%$

BINAP= 2,2'-bis(diphenylphosphinyl)-1,1'-binaphthalene

Figure 1. Ligands used in this study, and conversion to aldehyde obtained in the transfer hydroformylation of cisstilbene using $1 \mathrm{~mol} \% \mathrm{Rh}$ catalysts, $3 \mathrm{~mol} \%$ ligand, 6 equivalents of paraformaldehyde, at $120{ }^{\circ} \mathrm{C}$ for 45 minutes, as communicated in ref. 4. Toluene was used as solvent, and in those unsuccessful reactions significant amount of trans-stilbene were detected (see ref 4).

There are several reasons for the very low yields of aldehyde product for all of the catalysts except those derived from Ph-BPE: some catalysts might not survive the relatively high temperatures, or could lead to extensive isomerisation before hydroformylation takes place. Some catalysts might not operative well at the relatively low pressures of syngas generated, and/or some catalysts might not be able to produce sufficient syngas to operate properly. The substrate chosen was quite a poorly reactive alkene. It is difficult since one of the rate-determining parts of a conventional hydroformylation is the exchange of a $\mathrm{CO}$ ligand for an alkene. Anything other than a 1alkene tends to compete less successfully with $\mathrm{CO}$. In fact the results obtained with $\left[\mathrm{Rh}(\mathrm{acac})(\mathrm{CO})_{2}\right] / \mathrm{Ph}$ $\mathrm{BPE}$ on this less reactive alkene are quite remarkable since conventional hydroformylation using this catalyst after several attempts using normally optimal conditions did not give higher than $74 \%$ e.e. The ATHF therefore shows slightly different characteristics from conventional hydroformylation, probably as a result of the gradually produced low concentrations of $\mathrm{CO}$ being quite hard to achieve using a normal hydroformylation protocol in a sealed vessel.
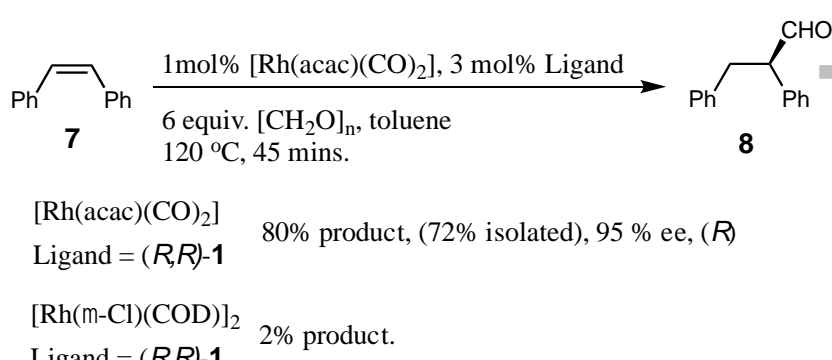

Scheme 1. ATHF of cis-stilbene using different Rh sources.

Using the same $\mathrm{Ph}-\mathrm{BPE}$ ligand and $\left[\mathrm{RhCl}(\operatorname{cod})_{2}\right]$ instead of $\left[\mathrm{Rh}(\mathrm{acac})(\mathrm{CO})_{2}\right]$ leads to almost no product (Scheme 1). The combination of $\left[\mathrm{RhCl}(\operatorname{cod})_{2}\right]$ anc $\mathrm{Ph}-\mathrm{BPE}$ is an excellent catalyst for decomposition of formaldehyde: based on simple experiments, using the pressure sensor in a chemical microwave to measure pressure build up without alkene present, it is superior to $\left[\mathrm{Rh}(\mathrm{acac})(\mathrm{CO})_{2}\right] / \mathrm{Ph}$-BPE. However, it seems likely that $\left[\mathrm{RhCl}(\mathrm{cod})_{2}\right]$ and $\mathrm{Ph}-\mathrm{BPE}$ only produce low levels of the most active hydroformylation catalyst, $\left[\mathrm{RhH}(\mathrm{CO})_{2}(\mathrm{Ph}-\mathrm{BPE})\right]$, or that this mixture converts to a less reactive hydroformylation catalyst of a different form. With a highly reactive terminal alkene substrate, like styrene, used in reference 5, then this catalyst works especially well (and we have been able to reproduce a typical protocol from reference 5 well). However, we had found that our most successful combination $\left[\mathrm{Rh}(\mathrm{acac})(\mathrm{CO})_{2}\right] / \mathrm{Ph}-\mathrm{BPE}$ does not promote ATHF of styrene very well due to low regioselectivity. From this we infer that that our preferred catalyst producer $\mathrm{CO}$ and hydrogen at a slow rate relative to styrene hydroformylation; this can lead to linear selectivity in the hydroformylation of styrene. ${ }^{[7]}$ However, for other alkenes, the use of $\left[\mathrm{Rh}(\mathrm{acac})(\mathrm{CO})_{2}\right]$, which is more commonly used in conventional hydroformylation catalysis, is more reactive and can deliver high selectivity.

In this paper we report on a project aimed at exploring the scope of the $\mathrm{Rh} / \mathrm{Ph}-\mathrm{BPE}$ system, and the development of conditions that allow the use of other chiral hydroformylation ligands in a syngas-free ATHF procedure. We hope that, in addition to 
providing useful catalytic methods for various targets, the findings should be enabling to other researchers who wish to develop a syngas-free hydroformylation reaction.

\section{Results and Discussion}

The $\left[\mathrm{Rh}(\mathrm{acac})(\mathrm{CO})_{2}\right]$ / Ph-BPE catalyst was reported in our original communication to give high yields in the transfer hydroformylation of a range of alkenes, but probably the most striking results were the ATHF of cis-stilbene and a few derivatives. The scope of this catalyst was first studied on the ATHF of some asymmetrically substituted cis-stilbene derivatives. Despite some achievements, ${ }^{[8]}$ there is a lack of predictability, and further research needed on the hydroformylation of non-symmetric alkenes in general.
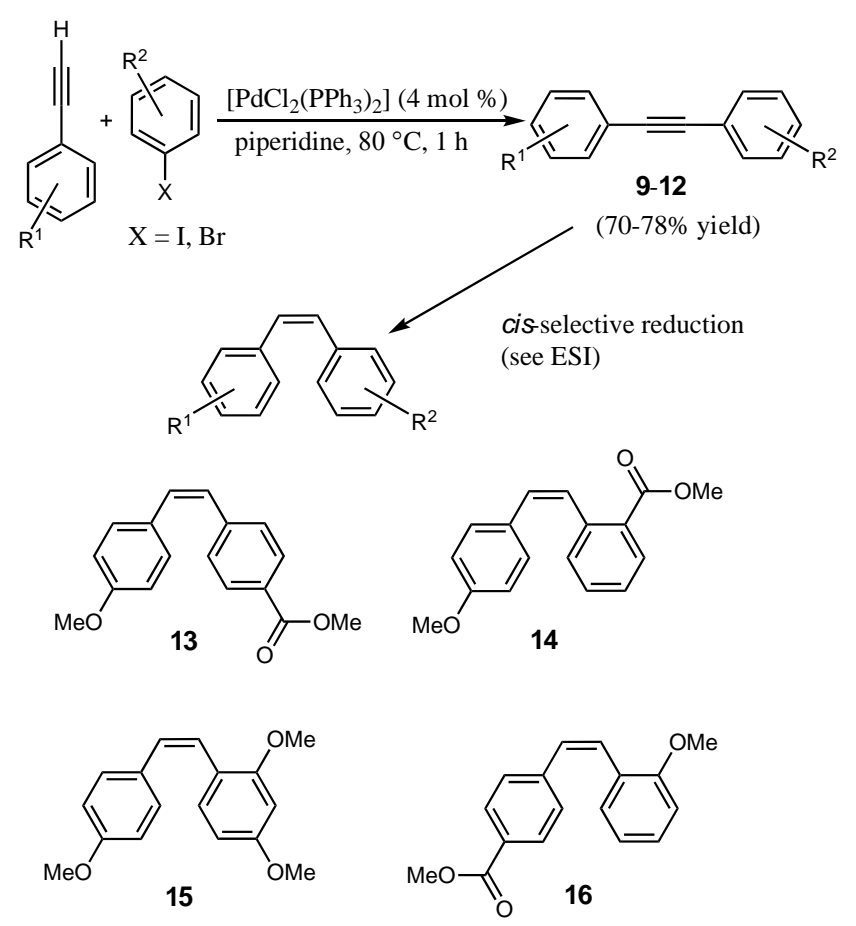

Scheme 2. The preparation of cis-stilbene derivatives used in this study.

For this reaction, we studied this aspect using four carefully chosen alkenes (Scheme 2). A two-step methodology was used to make the substrates: a Sonogashira cross-coupling reaction ${ }^{[9]}$ to give alkynes 9-12, followed by a cis-selective reduction. The latter step required different methods depending on the alkynes used, with the planned Lindlar reduction being replaced by a $\mathrm{Ti}$ mediated $^{[10]}$ or a $\mathrm{Pt}$ catalysed ${ }^{[11]}$ reduction adapted from the literature for 15 and 16 respectively. The synthesis of these alkenes is discussed in more detail in the ESI, but alkenes 1318 were prepared in sufficient quantity and purity to carry out the studies discussed.

Conventional hydroformylation of alkenes 13 -16 with a catalyst derived from $\left[\mathrm{Rh}(\mathrm{acac})(\mathrm{CO})_{2}\right]$ and

\section{1,3,5,7-tetramethyl-2,4,8-trioxa-6-}

phosphaadamantane ${ }^{[12]}$ was carried out. This gave a preliminary indication of the regioselectivity that these substrates might favour. These results are shown and discussed in more detail in the ESI; conversion and chemselectivity was good, and selectivities were around 2:1. The two regioisomers were found to be inseparable. The aldehydes were reduced with $\mathrm{NaBH}_{4}$ to an inseparable mix of the regioisomeric alcohols, which could be resolved by analytical chiral HPLC. The identity of the major and minor aldehyde (or alcohol) could be assigned through the use of ${ }^{1} \mathrm{H}^{-13} \mathrm{C}$ HMBC NMR.

Conventional asymmetric hydroformylation using syngas and chiral $\mathrm{Rh}$ catalysts was studied and is described in the ESI; despite many variations in conditions, AHF did not lead to promising results with these challenging substrates. The long reaction times necessary for AHF often led to full consumption of the starting material but also isomerisation to the $(E)$-alkene and low enantioselectivity. ATHF was studied next, which gave higher conversion, as described below.

The initial ATHF reactions were explored with alkene 13. The standardised conditions $\left(120^{\circ} \mathrm{C}, 1 \mathrm{~h}\right.$, $\left[\mathrm{CH}_{2} \mathrm{O}\right]_{n}$ (6 eq.) observed $55 \%$ conversion to the aldehydes, with a 64:36 regioselectivity favouring aldehyde $\mathbf{1 7}$ with $41 \%$ e.e but $90 \%$ e.e for the minor component, 18 (Table 1, entry 1). The lower e.e. for 17 is presumed to be a result of the more electronwithdrawing aryl ring adjacent to the formyl grou $_{\mathrm{r}}$ stabilising the enol tautomer, leading to racemisation under the reaction conditions. This decrease $\mathrm{i}$ selectivity (and conversion) is emphasised for longer reaction periods (Table 1, entry $2 \& 3$ ), despite usins a lower temperature (Table 1, entry 2). This is consistent with the observation that slower AHF reactions were unsuccessful with these substrates. Larger amounts of the trans-alkene are also noticeable at long reaction times, but with no increase in aldehyde yield. The possibility of dehydroformylation of the aldehydes to the more stable $(E)$-isomer as the cause was disproved (see ESI). Therefore, an alternative explanation may relate to decomposition of the catalyst over time, meaning only the simpler process of alkene isomerisation is possible. As a longer reaction time had a negative impact on the selectivity, we shortened the reaction time to 30 minutes, which led to increase in conversion to the aldehydes $(61 \%)$, regioselectivity (68:32) and enantioselectivity for $\mathbf{1 7}$ to $84 \%$ e.e. (Table 1, entry 4). The major regioisomer of the aldehyde, (17) forms adjacent to the electronwithdrawing methyl-ester; this is possibly due to the stabilisation of the negative charge built up during C$\mathrm{H}$ bond formation by the electron poor arene. 
Table 1. Asymmetric Transfer HydroFormylation of asymmetrically substituted $Z$-alkenes.

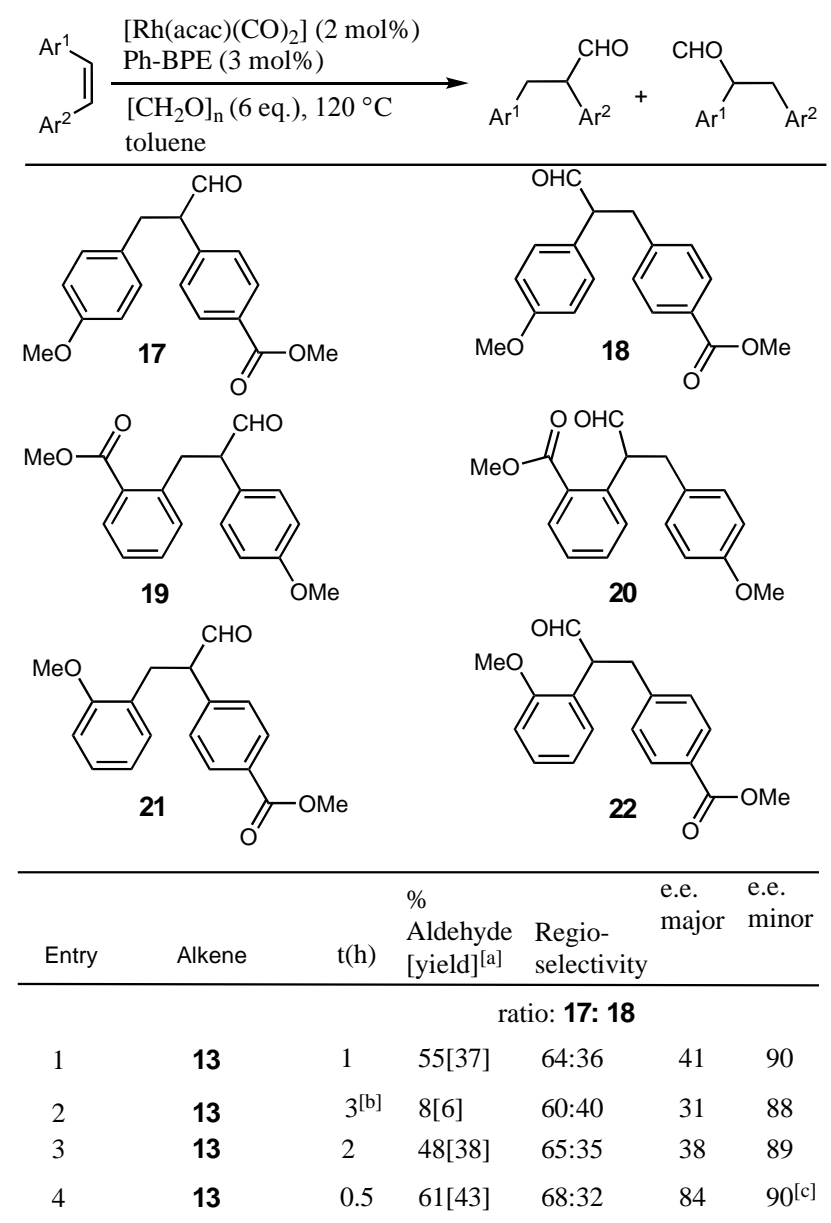

ratio: 19: 20

$\begin{array}{lllllll}5 & 14 & 1 & 31[27] & 68: 32 & 90 & \text { n.d. }\end{array}$

ratio: 21: 22

$\begin{array}{lllllll}6 & 16 & 1 & 65[35] & 65: 35 & 95 & 98\end{array}$

[a] Remaining mass balance is mainly $E$ isomer of alkene, except final 2 entries which are starting material.

$\%$ aldehyde determined by NMR spectroscopy against cyclooctane as internal standard. Isolated yield in square brackets are for the corresponding alcohols obtained after both hydroformylation and then $\mathrm{NaBH}_{4}$ reduction and chromatography (e.e. determined at this stage).

[b] $110^{\circ} \mathrm{C}$; ${ }^{[c]}$ result reported in communication (ref. 4).

ATHF of methyl (Z)-2-(4-methoxystyryl)benzoate, 14, gave lower product yield, and favours aldehyde $1931 \%, \mathbf{1 9 : 2 0}=68: 32$ ). Both of these observations can be rationalised as being due to the sterically bulky ortho substituent hindering the coordination of the alkene to the metal centre. Enantioselectivity was excellent (Table 1, entry 5). ATHF of alkene $\mathbf{1 6}$ obtained $65 \%$ conversion to the aldehydes and a 65:35 regioselectivity favouring aldehyde 21 . This regioselectivity again places the aldehyde away from an ortho substituent and also on the more electron deficient of the alkene carbons. Enantioselectivity was excellent: $95 \%$ e.e for the major isomer and $98 \%$ e.e for the minor isomer, reflecting good configuration stability (Table 1 , entry 6).

Table 2. Asymmetric Transfer Hydroformylation of alkene 15.

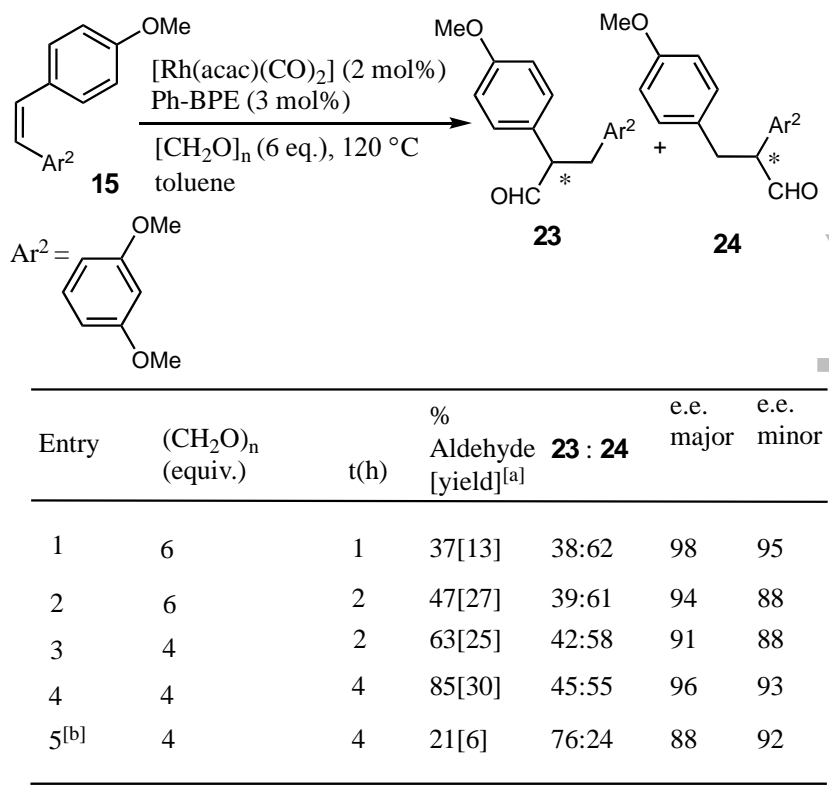

[a] Remaining mass balance is mainly starting material, except entry 2 $(15 \%)$ and entry $5(57 \%)$ Eisomer of alkene

$\%$ aldehyde determined by NMR spectroscopy against cyclooctane as internal standard. Isolated yield in square brackets are for the corresponding alcohols obtained after both hydroformylation and then $\mathrm{NaBH}_{4}$ reduction and chromatography (e.e. determined at this stage). ${ }^{[\mathrm{b}]}$ Ligand 4 (Fig 1) used in place of $(R, R$ )-Ph-BPE

Hydroformylation of alkene $\mathbf{1 5}$ is a possible new route to $(S)$-Equol $\{(3 S)-3-(4-h y d r o x y p h e n y l)-7-$ chromanol $\}.{ }^{[13]}$ ATHF of alkene 15, gave relatively low conversion to the aldehydes (37\%) using the standard conditions $\left(120^{\circ} \mathrm{C},\left[\mathrm{CH}_{2} \mathrm{O}\right]_{\mathrm{n}}(6\right.$ eq. $\left.), 1 \mathrm{~h}\right)$, as well as regioselectivity to the undesired regioisomer, 24 as the major product (38:62). This was also observed with AHF using [Rh]/Ph-BPE (see ESI). This is hypothesised to be due to the lack of electronic or steric bias. However, enantioselectivity was excellent, achieving $98 \%$ e.e for the major (undesired) isomer and 95\% for the minor (desired) (Table 2, entry 1). Using 4 equivalents of paraformaldehyde and increasing the reaction time, optimally to 4 hours, led to a higher conversion $(85 \%)$ (Table 2, entry 4). The conventional AHF of alkene 15 using the [Rh]/Bisdiazaphos, 4 catalyst $^{14}$ led to good regioselectivity towards the desired regioisomer, 2 (see ESI), but conversion to the aldehydes never exceeded $40 \%$ (up to $14 \%$ isolated yield of alcohol). The good selectivity made transfer hydroformylation using this ligand of great interest, since we hoped the lower pressures of $\mathrm{CO}$ might improve reactivity, whilst retaining selectivity. The ATHF reaction was run at $120{ }^{\circ} \mathrm{C}$ for 4 hours and delivered 74:26 regioselectivity towards the desired 
regioisomer, but gave low conversion and was accompanied by significant isomerisation to the $(E)$ alkene (Table 2, entry 5). The low conversion was ascribed to Bisdiazaphos being a poor ligand for the decarbonylation of paraformaldehyde into syngas.

This result highlights an issue with using a single ATHF catalyst: so few ligands are able to promote both the formaldehyde decomposition and hydroformylation reactions. As another example that illustrates this, branched selective hydroformylation of allyl benzene derivatives is of interest, but the $\mathrm{Rh} /$ Ph-BPE system has been reported to give low regioselectivity and low e.e. in AHF of this substrate. ${ }^{[15 \mathrm{a}]}$

It would therefore be a step forward if the asymmetric transfer hydroformylation reaction could be developed to utilise a dual catalyst system, where the decarbonylating ability of $\mathrm{Rh} / \mathrm{Ph}-\mathrm{BPE}$ could be combined with the selectivity of a different catalyst, in order to achieve optimum conversion and selectivity.

Table 3 Transfer hydroformylation of allyl benzene

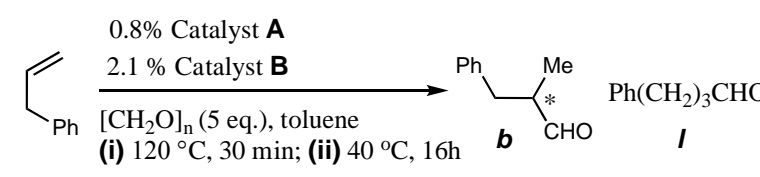

\begin{tabular}{|c|c|c|c|c|c|}
\hline & Catalyst A & Catalyst B & $\begin{array}{l}\text { Product } \\
(\%)^{[a]}\end{array}$ & $b: I$ & $\begin{array}{l}\text { e.e. } \\
(\%)\end{array}$ \\
\hline & $\begin{array}{l}0.8 \%[\mathrm{RhCl}(\mathrm{COD})]_{2} \\
0.9 \%(\mathrm{~S}, \mathrm{~S})-\mathrm{Ph}-\mathrm{BPE}\end{array}$ & $\begin{array}{l}2.1 \%\left[\mathrm{Rh}(\mathrm{acac})(\mathrm{CO})_{2}\right] \\
2.6 \%\left(S_{a x}, S, S\right)-2\end{array}$ & $40^{[b]}$ & $55: 45$ & 27 \\
\hline & $\begin{array}{l}0.8 \%[\mathrm{RhCl}(\mathrm{COD})]_{2} \\
0.9 \%(\mathrm{~S}, \mathrm{~S})-\mathrm{Ph}-\mathrm{BPE}\end{array}$ & $\begin{array}{l}2.1 \%\left[\mathrm{Rh}(\mathrm{acac})(\mathrm{CO})_{2}\right] \\
2.6 \%\left(S_{a x}, S, S\right)-2\end{array}$ & $96^{[c]}$ & 69:31 & 79 (S) \\
\hline (3) & N/A & $\begin{array}{l}2.1 \%\left[\operatorname{Rh}(\mathrm{acac})(\mathrm{CO})_{2}\right] \\
2.6 \%\left(S_{2 x}, S, S\right)-2\end{array}$ & $35^{[\mathrm{c}]}$ & $63: 27$ & $73(S)$ \\
\hline & $\begin{array}{l}0.8 \%[\mathrm{RhCl}(\mathrm{COD})]_{2} \\
0.9 \%(S, S)-\mathrm{Ph}-\mathrm{BPE}\end{array}$ & $\begin{array}{l}\left.2.1 \% \text { [ Rh(acac)(CO) })_{2}\right] \\
2.6 \% \text { (S,S)-Ph-BPE }\end{array}$ & $69^{[c, d]}$ & $40: 60$ & $2(S)$ \\
\hline & $\begin{array}{l}0.8 \%[\mathrm{RhCl}(\mathrm{COD})]_{2} \\
0.9 \% \text { dppe }\end{array}$ & $\begin{array}{l}2.1 \%\left[\mathrm{Rh}(\mathrm{acac})(\mathrm{CO})_{2}\right] \\
2.6 \% \text { (S,S)-Ph-BPE }\end{array}$ & $28^{[\mathrm{c}]}$ & $71: 29$ & $79(S)$ \\
\hline & $\begin{array}{l}0.8 \%[\mathrm{RhCl}(\mathrm{COD})]_{2} \\
0.9 \%(\mathrm{~S}, \mathrm{~S})-\mathrm{Ph}-\mathrm{BPE}\end{array}$ & $\begin{array}{l}2.1 \%\left[\mathrm{Rh}(\mathrm{acac})(\mathrm{CO})_{2}\right] \\
2.6 \%\left(R_{a x}, R, R\right)-2\end{array}$ & $67^{[\mathrm{c}]}$ & $74: 26$ & $81(R)$ \\
\hline
\end{tabular}

[a] \% aldehyde determined by NMR spectroscopy against methyl naphthalene as internal standard. e.e. determined on the corresponding alcohol obtained after both hydroformylation and $\mathrm{NaBH}_{4}$ reduction.

[b] alkene, formaldehyde and pre-mixed catalyst solution all added prior to step (i).

[c] alkene only mixed with catalysts after step (i)

[d] $10 \%$ isomerised internal alkene detected most catalysts give no selectivity or favour the linear aldehyde in hydroformylation of unbiased alkenes of this type, with the main exception being catalysts derived from ligand 2 that can give around $75-80 \%$ selectivity. ${ }^{[15]}$

ATHF of allyl benzene was studied, with a dual catalyst system. Simply combining a Rh source with ligand $\mathbf{2}$ along with a better formaldehyde decomposition catalyst $\mathbf{A},\left[\mathrm{RhCl}(\operatorname{cod})_{2}\right]$ and $(S, S)-\mathrm{Ph}$ BPE (Table 3, entry 1) was not effective. The key to getting improved results is the physical separation of the catalysts from the alkene inside a single vessel, allowing the decarbonylation reaction to generate syngas at high temperature, prior to mixing of the alkene with the hydroformylation catalyst after cooling to a lower temperature optimal for high selectivity. While such procedures are well-known functions that can be added to a commercial pressure reactor, a simple solution for laboratory scal procedures is described in the ESI and is what has been used here. This leads to an improvement from $40 \%$ aldehydes and low selectivity (Table 3 , entry 1 ) to high yield, $b: l$ of $2.1: 1$ and $79 \%$ e.e. (Table 3 entry $2)$. If catalyst $\mathbf{B}$, derived from $\left(S_{a x}, S, S\right)-\mathbf{2}$ is used without an addition formaldehyde decomposition catalyst, then a low yield is observed (Table 3, entry 3). As a control experiment, if both formaldehyde decomposition catalyst, $\mathbf{A}$ and hydroformylation catalyst $\mathbf{B}$ are derived from $(S, S)-\mathrm{Ph}-\mathrm{BPE}$, then the selectivity changes to favour the linear aldehyde slightly, along with producing some prop-1-en-yl benzene (Table 3, entry 4). The enantioselectivit, was low, as was observed in previous work using syngas as reagent. ${ }^{[15 a]}$ It stands to reason that racemi Ph-BPE would be equally effective as the single enantiomer in the formaldehyde decomposition, bu: since this work was aimed at organic synthesis laboratories, we have only used the commercially available single enantiomer. Unfortunately, changing catalyst $\mathbf{A}$ to utilise the achiral ligand dppe (dppe = 1,2-bis diphenylphosphinoethane), reduces yield (Table 3, entry 5, see ESI for some other examples). It is clear that catalyst $\mathbf{B}$ alone carries out the hydroformylation step, despite the presence of another $\mathrm{Rh}$ catalyst in the same solution, since the mix of catalyst $\mathbf{B}$ and achiral dppe-derived catalyst $\mathbf{A}$ in entry 5 gives similar enantioselectivity to that shown in entry 2. To further support this, if the enantiomer of ligand $\mathbf{2}$ in catalyst $\mathbf{B}$ is switched, while keeping the $(S, S)$ enantiomer of Ph-BPE in catalyst $\mathbf{A}$, similar enantioselectivity towards the opposite enantiomer of product is observed (Table 3 , entry 6). In summary, while the normal conditions are not at all useful for an isomerisation prone substrate like allyl benzene, this dual catalyst system with the alkene mixed only after syngas has been generated leads to significantly improved results, if not matching optimised conditions using syngas; this was then examined on other substrates to see if it has general use. 
In 2017, we published work describing a tandem hydroformylation-cyclisation reaction of allylglycine derivatives $^{[16]}$ to either hemi-aminal or hemi-acetals; the products could be converted to intermediates for the synthesis of an intermediate to the antibiotic, Nemonoxacin. ${ }^{[17]}$ The AHF of $(S)$-allylglycinol, 25, using a $\mathrm{Rh} /(R, R, R)-2$ catalyst at 5 bar syngas pressure achieves high conversion and selectivity ( $>99 \%$ conversion to products, $b: l=4.9: 1$, d.r $=93: 7$ ) (Table 4, entry 1). The original ATHF conditions using the $[\mathrm{Rh}] / \mathrm{Ph}-\mathrm{BPE}$ catalyst were tested for comparison. Standard ATHF conditions using $[\mathrm{Rh}] / \mathrm{Ph}-\mathrm{BPE}$ gave a b:1 of just 60:40 (Table 4, entry 2 ). The dual catalyst procedure, as described in Table 3 , entry 2 , with $(R, R, R)-2$ as the hydroformylation component of the catalyst gave $91 \%$ consumption of the starting material to obtain $75 \%$ hemiacetal, 26 and 16\% linear aldehyde, 27 (i.e. a B:L of 82:18, Table 4, entry 3). With an effective $b: l$ of $4.7: 1$, this is comparable to the results achieved in AHF (4.9:1). However, there was a slight decrease in diastereoselectivity, $\left(\right.$ d. $r=86: 14$, determined from ${ }^{1} \mathrm{H}$ NMR after oxidation to the lactone using $\mathrm{Ag}_{2} \mathrm{CO}_{3} /$ Celite). The results from table 3 and 4 illustrate that a dual catalyst system derived from ligands $\mathbf{1}$ and $\mathbf{2}$ is clearly potentially useful. Nonethe-less, conversion and selectivity was slightly below that observed for AHF using Rh / $(R, R, R)-2$. This may be due to the partial decomposition of ligand $\mathbf{2}$ under the harsher conditions of the activation (120 ${ }^{\circ} \mathrm{C}$ for 30 minutes).

Table 4. AHF and ATHF of (S)-allyl glycinol.

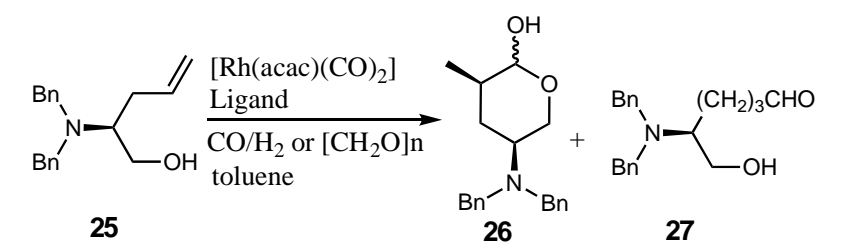

\begin{tabular}{|c|c|c|c|}
\hline Procedure & Conversion & $\begin{array}{c}\text { b: } 1 \\
\text { (26: 27) }\end{array}$ & d.r. ${ }^{[\mathrm{a}]}$ \\
\hline $\begin{array}{l}\text { Entry 1: }[\mathrm{b}] \\
0.4 \mathrm{~mol} \%\left[\mathrm{Rh}(\mathrm{acac})(\mathrm{CO})_{2}\right], \\
2 \mathrm{~mol} \%(R, R, R)-2 \\
40^{\circ} \mathrm{C}, 5 \text { bar syngas, } 16 \mathrm{~h}\end{array}$ & $>99$ & $83: 17$ & $93: 7$ \\
\hline $\begin{array}{l}\text { Entry 2: } \\
2 \mathrm{~mol} \%\left[\mathrm{Rh}(\mathrm{acac})(\mathrm{CO})_{2}\right], \\
3 \mathrm{~mol} \%(\mathrm{~S}, \mathrm{~S})-\mathrm{Ph}-\mathrm{BPE} \\
120^{\circ} \mathrm{C}, 6 \text { equiv. }\left(\mathrm{CH}_{2} \mathrm{O}\right)_{\mathrm{n}}, 1 \mathrm{~h}\end{array}$ & $>99$ & $60: 40$ & $85: 15$ \\
\hline $\begin{array}{l}\text { Entry 3: }[\mathrm{c}] \\
2.1 \mathrm{~mol} \%\left[\mathrm{Rh}(\mathrm{acac})(\mathrm{CO})_{2}\right], \\
2.6 \mathrm{~mol} \%(R, R, R)-2 \\
0.8 \mathrm{~mol} \%[\mathrm{RhCl}(\mathrm{cod})]_{2} \\
0.9 \mathrm{~mol} \%(\mathrm{~S}, \mathrm{~S}-\mathrm{Ph}-\mathrm{BPE} \\
6 \text { equiv. }\left(\mathrm{CH}_{2} \mathrm{O}\right)_{\mathrm{n}}, \\
120^{\circ} \mathrm{C}(0.5 \mathrm{~h}), 40^{\circ} \mathrm{C} 16 \mathrm{~h}\end{array}$ & 91 & $82: 18$ & $86: 14$ \\
\hline
\end{tabular}

[a] d.r. determined by ${ }^{1} \mathrm{~h}$ NMR spectrsocopy on the lactone obtained after oxidation with $\mathrm{Ag}_{2} \mathrm{CO}_{3}{ }^{[\mathrm{b}]}$ result reproduced from ref. $16^{[\mathrm{c}]}$ dual catalyst process with delayed mixing of alkene.
We extended the dual catalyst methodology to two other catalysts. For example, we felt a catalyst system of $\left[\mathrm{Rh}(\mathrm{acac})(\mathrm{CO})_{2}\right] / \mathrm{Bisdiazaphos}, 4-[\mathrm{Rh}(\mathrm{cod}) \mathrm{Cl}]_{2} / \mathrm{Ph}$ BPE would be particularly advantageous for the hydroformylation of alkene $\mathbf{1 5}$, as a catalyst derived from ligand $\mathbf{4}$ produced higher regioselectivity to the desired isomer for the synthesis of $(S)$-equol. A similar dual catalyst protocol as described in Table 3, entry 2 was used, although the reaction was carried out at $70{ }^{\circ} \mathrm{C}$ for 16 hours; this achieved high conversion to the aldehydes (81\%), excellent enantioselectivity $(96 \%$ for the major, $\mathbf{2 3}, \mathbf{9 2 \%}$ for the minor, 24) and retained the better regioselectivity to the desired regioisomer (75:25) (Scheme 3, right). This methodology also benefitted another of the cisstilbene derivatives, 14, that only obtained low conversion $(31 \%)$ and adequate regioselectivity $(68: 32)$ in the standard ATHF using $\left[\mathrm{Rh}(\mathrm{acac})(\mathrm{CO})_{2}\right] / \mathrm{Ph}-\mathrm{BPE}$. A significant increase in conversion to the aldehydes $(70 \%)$, regioselectivity (90:10) and enantioselectivity (96\% for the major aldehyde, 19) (Scheme 3, left) was achieved after 16 hours at $70{ }^{\circ} \mathrm{C}$. These results suggest that the $[\mathrm{Rh}] /$ Bisdiazaphos, 4 catalyst can be used in a syngas-free methodology.

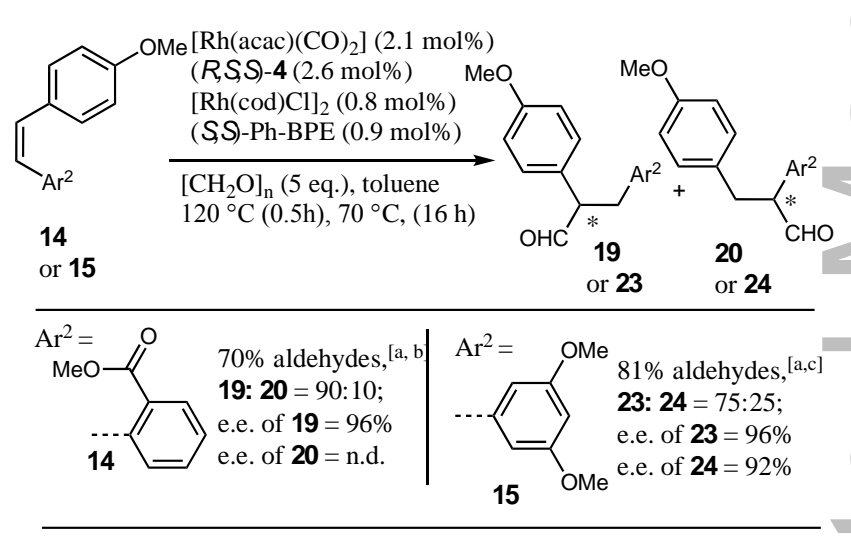

${ }^{[\mathrm{a}]}$ Remaining mass balance is predominantly $E$-alkene and some alkane. ${ }^{[b]}$ A yield of 50\% for alcohol formed after hydroformylation and $\mathrm{NaBH}_{4}$ reduction.

${ }^{\text {[c] }}$ A yield of $52 \%$ for alcohol formed after hydroformylation and $\mathrm{NaBH}_{4}$ reduction.

Scheme 3. ATHF of cis-stilbenes $\mathbf{1 5}$ and $\mathbf{1 6}$ using a dual catalyst system.

We also investigated another catalyst in this duar catalyst methodology: [Rh]/Kelliphite, ${ }^{[18]}$ which has previously obtained very selective results in the AHF of Boc-lactam 28 (>99\% conv, 29:30 = 7.5:1 $\left(50{ }^{\circ} \mathrm{C}\right.$, $1 \mathrm{~h})$, or $9.4: 1\left(15^{\circ} \mathrm{C}, 16 \mathrm{~h}\right) .^{[19]}$ This substrate was also investigated in 2015 using the standard ATHF reaction using $[\mathrm{Rh}] / \mathrm{Ph}-\mathrm{BPE}$, and although a full conversion was observed in only 5 minutes, it is at the expense of a lower selectivity (>99\% conversion, $\mathrm{b}: 1=2.5: 1$ on purification).

Conducting the reaction using the dual catalyst protocol with delayed mixing of alkene introduced 
earlier, using $\left[\mathrm{Rh}(\mathrm{acac})(\mathrm{CO})_{2}\right] /(R, R)$-Kelliphite and $[\mathrm{Rh}(\operatorname{cod}) \mathrm{Cl}]_{2} /(S, S)-\mathrm{Ph}-\mathrm{BPE}$ led to full conversion to the aldehydes and high selectivity towards 29 (7.3:1), isolating the nearly isomerically pure $\mathbf{2 9}$ in $64 \%$ yield (Scheme 4). This outperforms the results from the standard ATHF reaction and is comparable to those achieved using AHF.

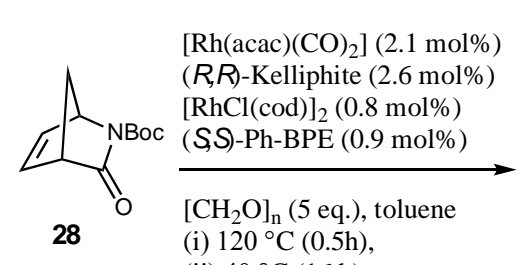

(ii) $40^{\circ} \mathrm{C}(16 \mathrm{~h})$

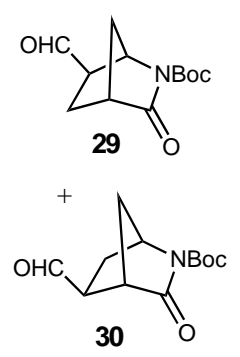

$>99 \%$ conversion, $\mathbf{2 9 : 3 0}=\mathbf{3} .3: 1$ $64 \%$ yield (13.3:1) on purification)

Scheme 4. ATHF of a bicyclic lactam using a dual catalyst system.

\section{Conclusion}

In this paper, we have studied the performance of the $\mathrm{Rh} / \mathrm{Ph}$-BPE catalyst in formal asymmetric transfer hydroformylations in greater detail. High enantioselectivity can be realised in the ATHF of cisstilbene derivatives, but sometimes yields or regioselectivity are not optimal. In order to allow a broader range of ligands to be used in ATHF, a dual catalyst system was developed. In this dual catalyst protocol we have used enantiopure $\mathrm{Ph}-\mathrm{BPE}$ ligands in combination with $[\mathrm{RhCl}(\mathrm{COD})]_{2}$ to decompose paraformaldehyde into $\mathrm{CO}$ and hydrogen. The use of a single enantiomer here is purely since such ligands are available commercially, although the racemic analogues could undoubtedly be used. Using the dual catalyst system, the hydroformylation activity comes entirely from the ligand pre-mixed with $\left[\mathrm{Rh}(\mathrm{acac})(\mathrm{CO})_{2}\right]$, and hence in the best cases, regioselectivity, e.e. or d.r. levels are significantly higher than what could be realised using the original ATHF protocol for a range of substrates identified as problematic. It is hoped this not only provides some syngas-free protocols for the specific targets described, but is enabling for other workers who may wish to use syngas-free hydroformylations.

\section{Experimental Section}

CAUTION: We have never had any incidents with vials cracking due to excess pressure. In experiments carried out where pressure was measured in smaller $10 \mathrm{~mL}$ vessels, but using similar amount of formaldehyde, the largest pressure measured was 7 bar (observed in an example where no hydroformylation occurred to use up the gas). However, the pressure will be proportional to the volume of the vessel and the amounts of formaldehyde used, so any deviations from this protocol should be carried out in a vessel that can withstand the pressures encountered. A sealable tube ( 8 bar max pressure, $25 \mathrm{~mL}$ ) was charged with a 8 $\mathrm{mm}$ cross stirrer bar, paraformaldehyde $(126 \mathrm{mg}, 5$ eq.) and another small sample vial containing a flea stirrer bar. The vial was capped with a rubber septum and placed under three vacuum/Ar cycles. A solution of the alkene $(0.84 \mathrm{mmol})$ in toluene $(1 \mathrm{~mL})$ and 1 methylnapthalene $(0.05 \mathrm{~mL})$ was made up in a Schlenk vial under an inert atmosphere. This was transferred into the small sample vial inside the sealed tube via syringe. A small sample was and analysed by ${ }^{1} \mathrm{H}$ NMR spectroscopy $\left(\mathrm{C}_{6} \mathrm{D}_{6}\right)$ The catalyst stock solutions $\left(\left[\mathrm{Rh}(\mathrm{acac})(\mathrm{CO})_{2}\right](4.5 \mathrm{mg}\right.$, $0.018 \mathrm{mmol}, 2.1 \mathrm{~mol} \%$ )/ligand (e.g. for ligand 2: 14.1 $\mathrm{mg}, 0.022 \mathrm{mmol}, 2.6 \mathrm{~mol} \%)$ in toluene $(1 \mathrm{~mL})$ and $\left[[\mathrm{Rh}(\operatorname{cod}) \mathrm{Cl}]_{2}(1.7 \mathrm{mg}, 0.007 \mathrm{mmol}, 0.8 \mathrm{~mol} \%) / \mathrm{Ph}\right.$ BPE (3.8 mg, $0.008 \mathrm{mmol}, 0.9 \mathrm{~mol} \%$ ) in toluene (1 $\mathrm{mL})$ ) were made up separately in two Schlenk tubes under an inert atmosphere. These were transferred to the sealed tube (outside of the sample vial) via syringe and the rubber septum was placed with a fitted cap immediately. The pressure vial was placed in an oil bath, and a blast shield was placed in front of the reaction. It was then heated to $120{ }^{\circ} \mathrm{C}$ for $30 \mathrm{~min}$ (stirring at speed $1000 \mathrm{rpm}$ ), before cooling for 30 min. (step (ii) in Table 3): The vial was then placed back into the oil bath for the desired time at a lower temperature before inverting the vial several times (to ensure the contents of the smaller vial are fully mixe. in). This was left to stir at the desired lower temperature for the desired time. The vial was coole to r.t and inverted several times before opening the vial. A small sample was taken and analysed by ${ }^{1} \mathrm{H}$ NMR spectroscopy $\left(\mathrm{C}_{6} \mathrm{D}_{6}\right)$ to calculate the conversion of the resulting aldehydes. The products were generally reduced as described in the ESI to deliver pure products after chromatography. The enantioselectivity of the reaction was determined by measuring e.e. on these corresponding primary alcohols using chiral HPLC. Full experimental details, analytical data, NMR and HPLC spectra can be found in the ESI (for compounds not previous communicated). Underpinning data (NMR files) are also available. ${ }^{[20]}$

\section{Acknowledgements}

Acknowledgements: The EPSRC doctoral training grant supported RP (DTG grant: 1518070)). The EPSRC (EP/M003868/1) is also acknowledged for funding (JAF\&PD). We thanks all the technical staff in St Andrews Chemistry for their assistance, and thank Dr Martin Fox (Dr Reddys (UK) for a fruitful discussion, and Dr Reddys (UK) for a gift of substrate $\mathbf{2 8 .}$

\section{References}

[1] a) P. W. N. M. van Leeuwen, in Rhodium Catalyzed Hydroformylation, Vol. 22 (Eds.: P. W. N. M. van 
Leeuwen, C. Claver), Springer Netherlands, 2002, pp. 1-13; b) R. Franke, D. Selent, A. Börner, Chem. Rev. 2012, 112, 5675-5732, c) A. Börner, R. Franke, in Hydroformylation. Fundamentals, Processes, and Applications in Organic Synthesis; Wiley-VCH Verlag GmbH \& Co. KGaA, 2016; d) L. Gonsalvi, A. Guerriero, E. Monflier, F. Hapiot, M. Peruzzini, in Hydroformylation for Organic Synthesis, Vol. 342 (Eds.: M. Taddei, A. Mann), Springer Berlin Heidelberg, 2013, pp. 1-47.

[2] a) T. Morimoto, K. Kakiuchi, Angew. Chem. Int. Ed.,2004, 43, 5580. b) T. Okano, T. Kobayashi, H. Konishi, J. Kiji, Tetrahedron Lett.,1982, 23, 4967. c) H. S. Ahn, S. H. Han, S. J. Uhm, W. K. Seok, H. N. Lee, G. A. Korneeva, J. Mol. Catal. A.,1999, 144, 295. d) L. Wu, Q. Liu, R. Jackstell, M. Beller, Angew. Chem. Int. Ed., 2014, 53, 6310. e) M. Rosales, A. González, B. González, C. Moratinos, H. Pérez, J. Urdaneta, R. A. Sanchez-Delgado, J. Organomet. Chem., 2005, 690, 3095. f) M. Rosales, F. Arrieta, P. Baricelli, A. González, B. González, Y. Guerrero, C. Moratinos, I. Pacheco, H. Pérez, J. Urdaneta, Catal. Lett., 2008, 126, 367; g) M. Uhlemann, S. Doerfelt, and A. Börner, Tetrahedron Lett. 2013, 54, 2209; h) E. Cini, E. Airau, N. Giraud, A. Mann, J. Salvadore, M. Taddei, Synlett, 2011, 199.

[3] G. Makado, T. Morimoto, Y. Sugimoto, K. Tsutsumi, N. Kagawa, K. Kakiuchi, Adv. Synth. Catal., 2010, 352, 299.

[4] J. A. Fuentes, R. Pittaway, M. L. Clarke, Chem. Eur. J., 2015, 21, 10645.

[5] T. Morimoto, T. Fujii, K. Miyoshi, G. Makado, H. Tanimoto, Y. Nishiyama, K. Kakiuchi, Org. Biomol. Chem., 2015, 13, 4632.

[6] A. T. Axtell, C. J. Cobley, J. Klosin, G. T. Whiteker, A. Zanotti-Gerosa, K. A. Abboud, Angew. Chem. Int. Ed. 2005, 44, 5834.

[7] I.A. Tonks., R. D. Froese., C. R. Landis., ACS Catal. 2013, 3, 12, 2905.

[8]For selected examples of regioselective hydroformylation of internal alkenes: a) M. K. T. Soltner, P. W. N. M. van Leeuwen, J. N. H. Reek, J. Am. Chem. Soc. 2006 128, 11344; b) T. Gadzikwa, R. Bellini, H. L. Dekker, J. N. H. Reek, J. Am. Chem. Soc. 2012 134, 2860; c) P. Dydio, R. J. Detz, J. N. H. Reek, J. Am. Chem. Soc 2013 135, 10817; P. Dydio, R. J. Detz, B. de Bruin, J. N. H. Reek, J. Am. Chem. Soc.
2014 136, 8418; d) C. Grünanger, B. Breit, Angew. Chem. Int. Ed. 2010, 49, 967; e) A. D. Worthy, M. M. Gagnon, M. T. Dombrowski, K. L. Tan, Org. Lett, 2009, 11, 2764; f) A. L. Watkins, B. G. Hashiguchi C. L. Landis, Org. Lett. 2008, 10, 4553; g) C. You, X. Li, Y. Yang, Y-S Yang, X. Tan, S. Li, B. Wei, H. Lv, L-W Chung, X. Zhang, Nat. Commun. 2018, 2045.

[9] a) N. E. Leadbetter, B. J. Tominack, Tetrahedron Lett. 2003, 44, 8653; b) See also: M. Alami, F. Ferri G. Linstrumelle, Tetrahedron Lett. 1993, 34, 6403

[10] Y. Obara, H. Moriya, M. Tokunaga, Y. Tsuji, J. Chem. Soc., Chem. Commun., 2003, 2820.

[11] A. Giraud, O. Provot, A. Hamze, J.-D. Brion, M. Alami, Tetrahedron. Lett., 2008, 49, 1107.

[12] R. A. Baber, M. L. Clarke, K. Heslop, A. Marr, A. G. Orpen, P. G. Pringle, A. M. Ward, D. A. ZambranoWilliams, Dalton Trans.,2005, 1079.

[13] a) J. M. Heemstra, S. A. Kerrigan, D. R. Doerge, W. G. Helferich, W A. Boulanger, Org. Lett., 2006, 8, 5441 and ref's therein. b) Y. Takashima, Y. Kobayashi, Tetrahedron Lett., 2008, 49, 5156. c) S. Yang, S. Zhu, C. Zhang, S. Song, Y. Yu, S. Li, Q. Zhou, Tetrahedron. 2012, 68, 5172.

[14] T. P. Clark, C. R. Landis, S. L. Freed, J. Klosin, K. A. Abboud, J. Am. Chem. Soc., 2005, 127, 5040.

[15] a) G. N. Noonan, J.A. Fuentes, C. J. Cobley M. L. Clarke, Angew. Chem. Int. Ed., 2012, 51, 2477. b) P. Dingwall, J. A. Fuentes, L. Crawford, A. M. Z. Slawir M. Bühl, M. L. Clarke, J. Am. Chem. Soc. 2017, 139, $15921-15932$; c) $(S, S, S)$-BOBPHOS is commerciall available from Strem Chemicals.

[16] R. Pittaway, J. A. Fuentes, M. L. Clarke, Org. Letı. 2017, 19, 2845.

[17] a) A. Arjona, Drugs Future., 2009, 3, 196. b) H. Ming-chu, R. K. Chi-Hsin, C. Shu-Jen, L. Lin, U.S. Patent US8211909 B2, 2012.

[18] C. J. Cobley, K. Gardner, J. Klosin, C. Praquin, C. Hill, G. T. Whiteker, A. Zanotti-Gerosa, J. L. Petersen, K. A. Abboud, J. Org. Chem. 2004, 69, 4031.

[19] G. M. Noonan, C. J. Cobley, T. Lebl M. L. Clarke, Chem. Eur. J. 2010, 16, 12788.

[20] The research data underpinning this publication can be accessed at https://doi.org/10.17630/e491713d9de2-4fa4-8853-4d7ce2656cfd 


\section{FULL PAPER}

CO-free Enantioselective Hydroformylation of Functionalised Alkenes: Using a Dual Catalyst System to give Improved Selectivity and Yield

Adv. Synth. Catal. Year, Volume, Page - Page

Rachael Pittaway, ${ }^{\text {a }}$ Paul Dingwall, ${ }^{\text {b José. A. }}$ Fuentes, ${ }^{\text {a }}$ Matthew. L. Clarke*

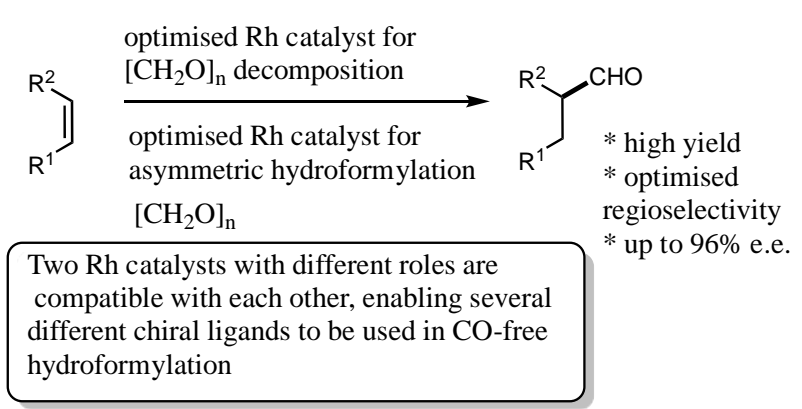

